\author{
Chapter 7 \\ WAVE HEIGHT MEASURING EQUIPMENT \\ E. H. Boiten \\ Instituut T.N.O. Voor \\ Werktuigkundige Constructies \\ Delft, Holland
}

The equipment was designed to obtain data from sea waves. It was developed by the Organization for Applied Scientific Research at Delft in coordination with the Royal Dutch Navy. The intention of the measurements with the wave height measuring equipment was to es tablish a correlation between the sea motion and the movements of a ship, which is steaming in that sea. So wave measurements and measurements of the ship movements were always carried out simultaneously. To have the movement of the ship free from the position of the wave meter, a telemetering system was chosen to transmit the data from the wave meter. The receiving and recording instruments are placed on board the ship.

The first measurement was made in December 1958. At that moment, the wate meter consisted of a buoy assembly in which was mounted a transmitter coupled with an accelerometer. The accelerometer measured the accelerations of the wave meter in a direction perpendicular to the water surface. The carrier of the transmitter was direct frequency modulated by the signal of the accelerometer.

After this measurement it became desirable to gather more data from the sea waves. For that reason the instrumentation of the wave meter was extended with a gyro, which measures the slope of the waves. The slope is determined by the angles of the water surface with respect to the horizontal plane in two directions perpendicular to each other. The angle signals frequency-modulate two subcarriers, which in their turn amplitude-modulated the transmitter carrier.

With this more complicated equipment a measurement was made in November 1959. In this paper a description is given of the instrumentation of the wave meter and the receiving and recording equipment as it is at the present with a slightly changed modulating system. As the data from the wave meter could be used to study only the wave motion apart from the ship, it seems reasonable to present this paper at this conference. 


\section{WAVE HEIGHT MEASURING EQUIPMENT}

\section{CONSTRUCTION OF WAVE METER}

The floating element of the wave meter is a $9 \mathrm{ft} \times 6 \mathrm{ft}$ aluminum raft. The housing of the accelerometer-transmitter and its batteries are suspended in the raft by means of a steel frame (Fig. 1). On the transmitter housing a removable mast is mounted with a length of about 16 feet. On top of the mast is the antenna. To put the center of gravity as low as possible and to obtain sufficient damping, the buoy was provided with a steel base plate of about 200 pounds. The natural frequency of the completed buoy showed to be about $0.5 \mathrm{c} . \mathrm{p} . \mathrm{s}$. The damping was nearly critical. On the base plate the other instruments are mounted in four watertight boxes. Figure 2 shows the unit on board a ship.

\section{INSTRUMENTATION OF WAVE METER}

General scheme of instrumentation. The complete block diagram of the wave meter instrumentation is given in Figure 3 . The accelerometer is of the capacitive type. The capacity is connected into the tuned circuit of an oscillator, generating a frequency of about $80 \mathrm{Mc} / \mathrm{s}$. A change of capacitance due to an acceleration changes the oscillator frequency, the frequency change being proportion to the acceleration. The transmitter consists of the oscillator as mentioned, followed by a doubler stage and a power stage. It is evident, that the transmitter is $\mathrm{f} . \mathrm{m}$. modulated by the accelerometer.

The angles of the wave meter-raft with the horizontal plane are measured by the gyro in two perpendicular directions: the roll angle and the pitch angle. The output voltages of the gyro, which are proportional to these angles modulate the frequency of two subcarrier oscillators. The subcarriers are added, amplified and fed into a ferrite modulator, connected into the oscillator tuned circuit of the transmitter. In this way, the oscillator of the transmitter is also $\mathrm{f} . \mathrm{m}$. modulated by the subcarriers. So the system is a mixed $\mathrm{f} . \mathrm{m}$. and f.m. - f.m. system. Power is obtained from accumulators. In the following sections more details about different building blocks of the wave meter instrumentation are given.

The accelerometer. The construction of the accelerometer is given in Figure 4. A mass is fixed in a casing by means of two membranes. The space between the mass and the casing is filled with oil. In this way a mass-spring system is obtained, which is nearly critically damped. The mass carries the grounded plate of a condenser. The is olated plate can be screwed up or down to adjust the plate distance and therewith the capacitance of the condenser. 
COASTAL ENGINEERING
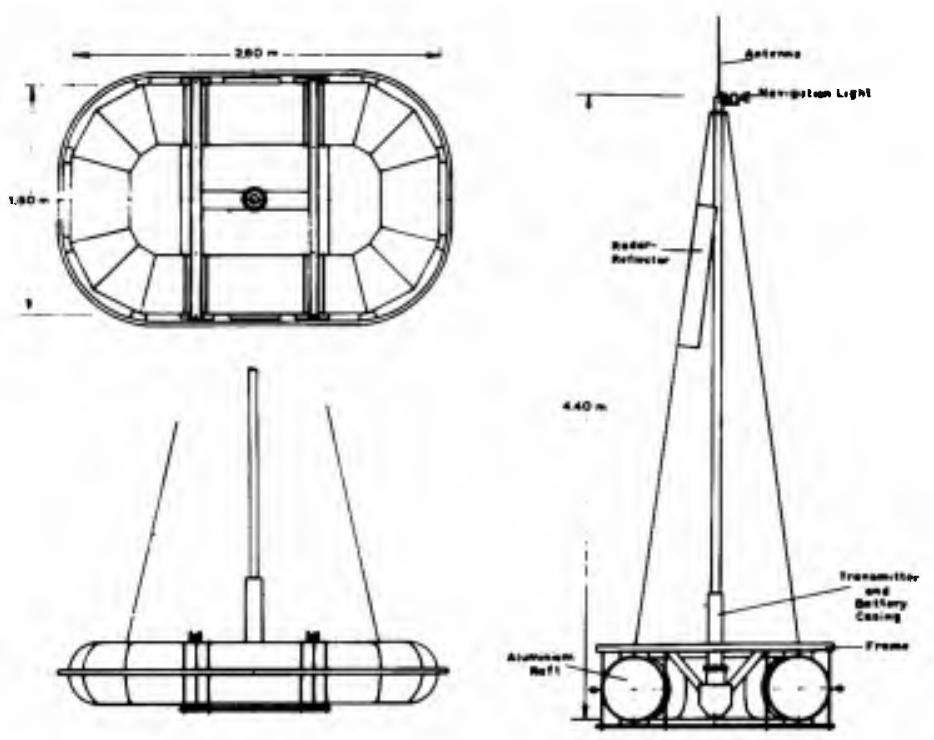

Fig. 1. Construction of the buoy-assembly .

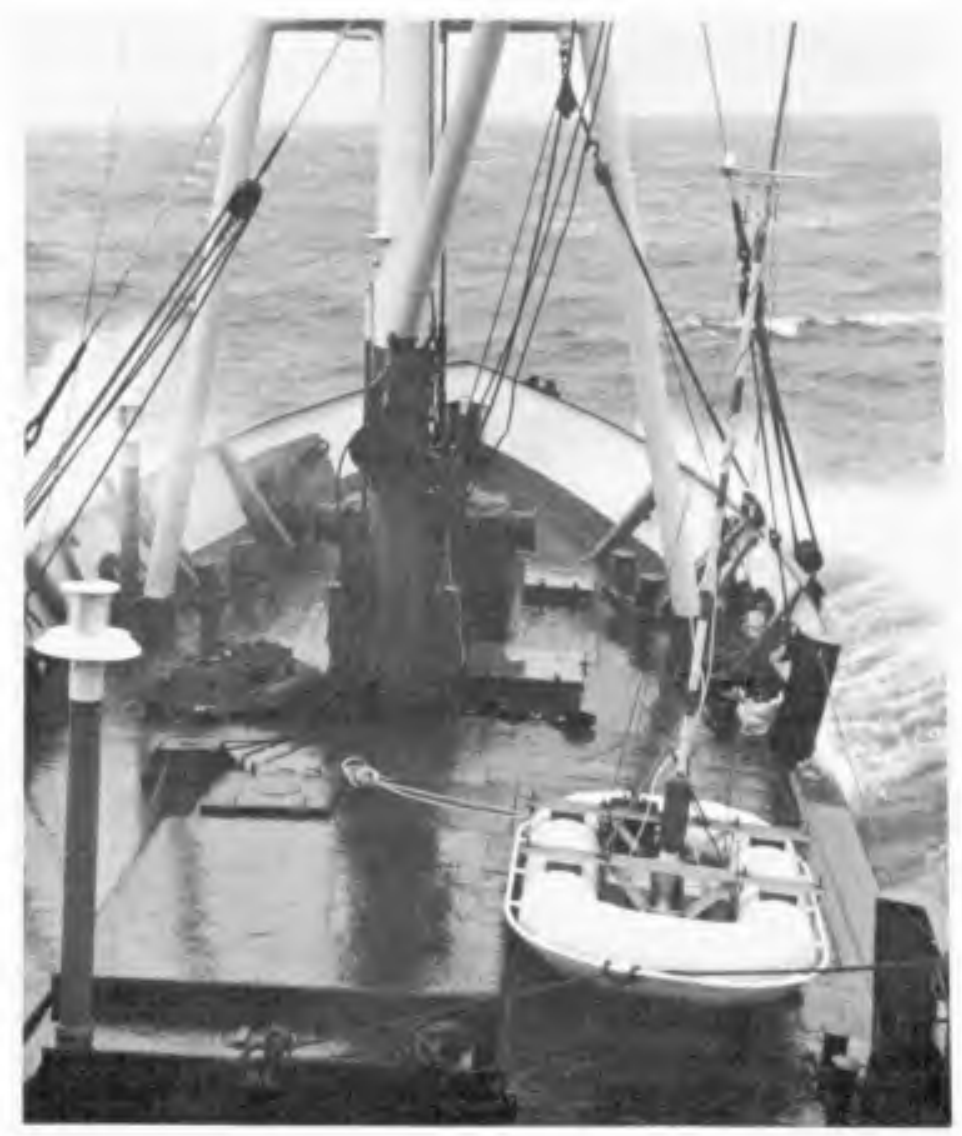

Fig. 2. Wave metér prior to launching. 
WAVE HEIGHT MEASURING EQUIPMENT

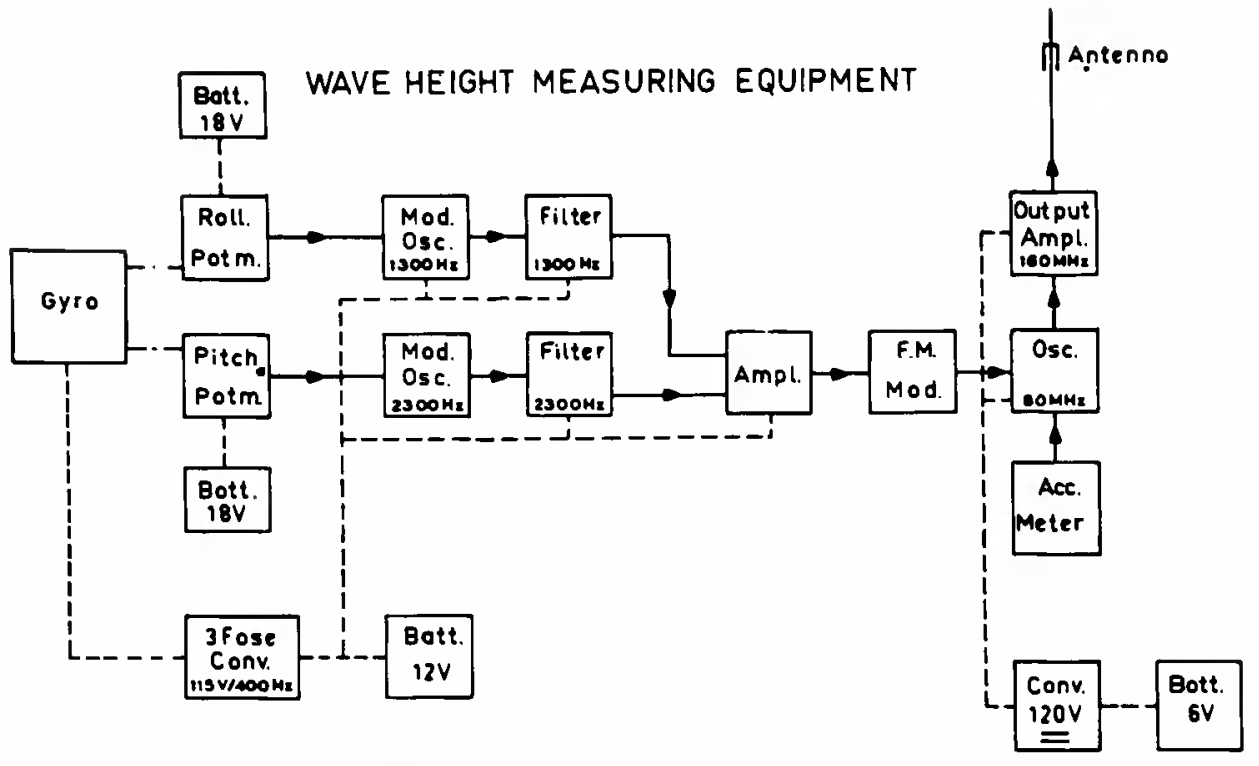

Tronsmitting instruments

Fig. 3. Block diagram of wave meter instrumentation.

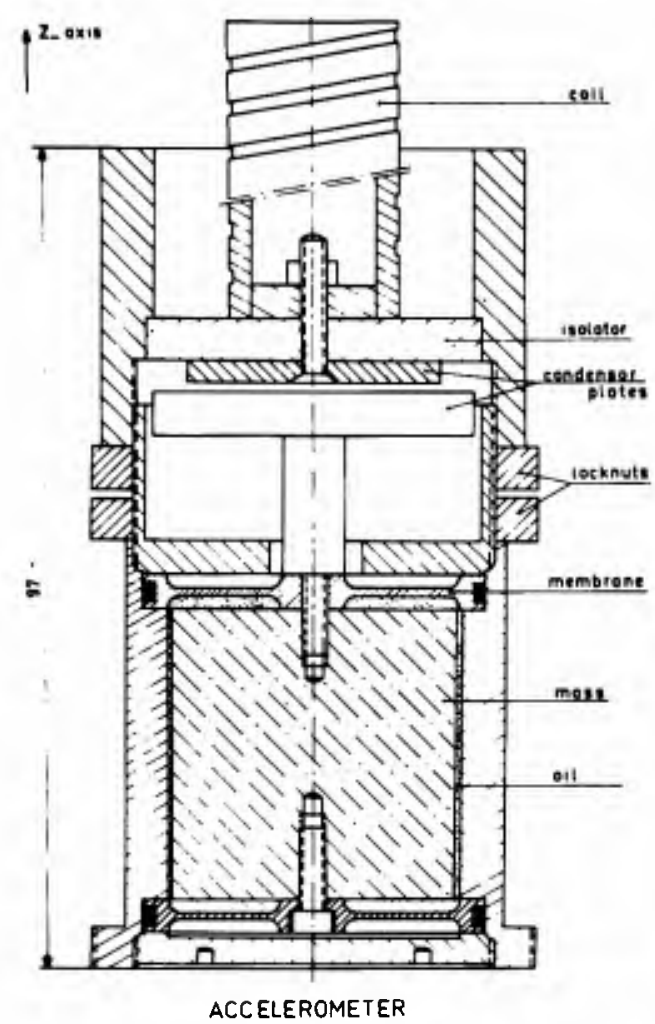

Fig. 4. Construction of the accelerometer.

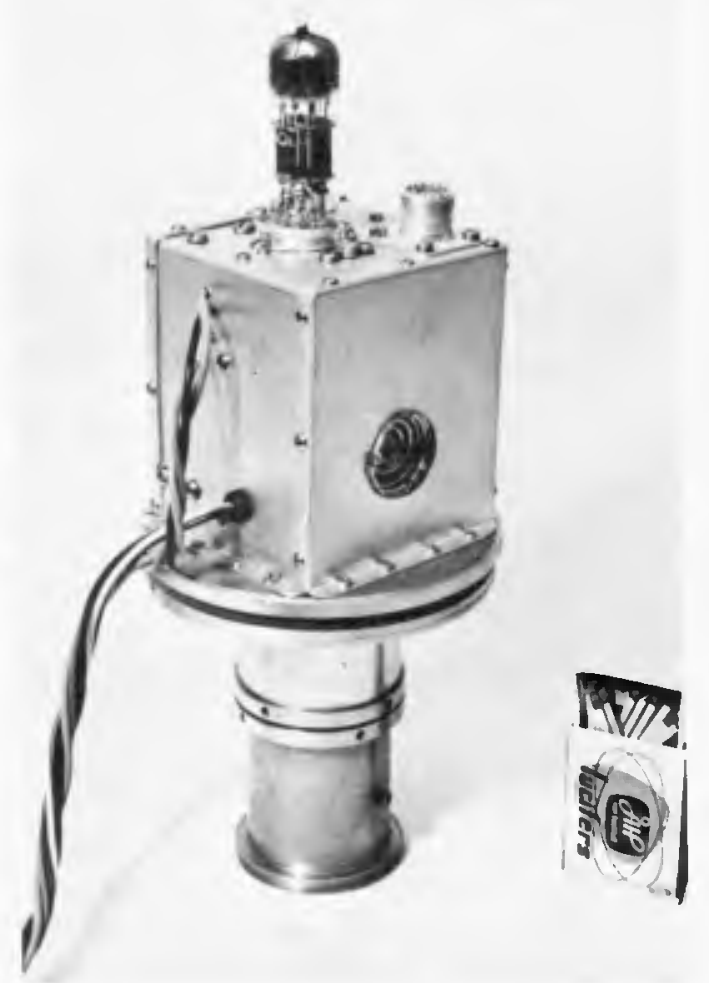

Fig. 5. Transmitter on top of accelerometer. 


\section{COASTAL ENGINEERING}

The resonant frequency of the mass -spring system is about $150 \mathrm{c} / \mathrm{s}$ Since the frequency spectrum of the accelerations to be measured is below $15 \mathrm{c} / \mathrm{s}$, no differences between static and dynamic deflections are to be expected. The static deflection (in the $1 \mathrm{~g}$ gravitational field) is $10 \mu \mathrm{m}$.

The transmitter. The transmitter consists of two stages: an oscillator/ doubler stage, and a power stage. The oscillator circuit is of the Colpitt type, oscillating in the screen-grid circuit of an E $180 \mathrm{~F}$ tube at about $80 \mathrm{Mc} / \mathrm{s}$. The frequency of the circuit is modulated by the varying capacitance of the accelerometer, and by the varying self inductance of a ferrite modulator, to which the subcarrier voltages, containing the gyro angle information are supplied. The anode circuit of the E $180 \mathrm{~F}$ tube is tuned to twice the oscillator frequency and is coupled to the power stage, which contains a double tetrode tube QQE 02/5 operating in push-pull connection. The anode circuit of the QQE 02/5 delivers power to a vertical dipole antenna. formula

Frequency shift and acceleration are related as shown in the

$$
\frac{\Delta f}{f}=-K \cdot \frac{m}{c \cdot d s t} \cdot(a+g)
$$

in which:

$$
\begin{aligned}
\Delta f & =\text { frequency shift } \\
f & =\text { central frequency } \\
K & =\text { dimensionless constant, depending on circuit constants } \\
\mathbf{m} & =\text { accelerometer mass } \\
\mathbf{C} & =\text { apring constant of accelerometer membranes } \\
\mathbf{d}_{\mathbf{S t}} & =\text { statioal displacement constant of accelerometer } \\
\mathbf{a} & =\text { acceleration to be measured } \\
\mathbf{g} & =\text { acceleration of gravitational field }
\end{aligned}
$$

D.C. power for the transmitter is obtained from a transistor DC-DC converter, fed by Ni-Cd accumulators. These accumulators were chosen because of their flat load characteristic. Figure 5 shows the transmitter with the accelerometer. 


\section{WAVE HEIGHT MEASURING EQUIPMENT}

Specifications of the transmitter are:

Central frequency

Adjustment range of frequency

Stability:

Frequency drift ( $2 \mathrm{hrs}$ after switching on)

Frequency fluctuations

Frequency change for $10 \%$ heater voltage variation

Frequency change for $10 \%$ anode voltage variation

Sensitivity (freq. shift/acceleration)

Power in antenna
157.75. $\mathrm{Mc} / \mathrm{s}$

$500 \mathrm{Kc} / \mathrm{s}$

$4.10^{-5} /$ hour

$10^{-5}$

$-10^{-4}$

The angle transducers. Since the wave height is to be derived from the vertical acceleration by double integration, there will be an error, when the accelerometer axis is not vertical. This error can be calculated, when the angle between the accelerometer axis and the true vertical direction is known.* For these reasons a gyro is included in the instrumentation. The gyro measures the angles of the wave meter raft with the horizontal plane in two perpendicular directions (roll angle and pitch angle). The angle of the accelerometer axis with the true vertical direction can then be computed from the formula

$$
\cos ^{2} \gamma+\sin ^{2} \delta_{r}+\sin ^{2} \delta_{p}=1
$$

in which

$\boldsymbol{\gamma}=$ angle between accelerometer axis and true vertical direction

$\delta_{r}=$ roll angle

$\delta_{\mathrm{p}}=$ pitch angle

The gyro-axis is erected and kept vertical by two erectionmotors, controlled by mercury switches. Since the erection-motors act very slowly, the reference for the gyro-axis is the direction of the total acceleration, averaged over several minutes.

In the wave meter the gyro is subjected to accelerations of constantly changing directions. However, the average is the true vertical direction, so when the erection motors act alowly enough the gyro axis direction will be very close to the vertical direction and

*There is some evidence that this error is not significant. It is however of importance to ascertain this. Besides this, it is desirable to know the wave slope, from which information may be obtained on the incidence of power on e.g.a ship's hull. 


\section{COASTAL ENGINEERING}

can be used as a reference for the true vertical direction. Roll and pitch angles are measured by potentiometers, coupled to the roll axis and pitch axis of the gyro gimbals and connected to constant voltage Ni-Cd batteries. The $115 \mathrm{~V} 400 \mathrm{c} / \mathrm{s}$ power for the gyro-motor is obtained from a three phase transistor DC-AC converter. Figure 6 shows the gyro-unit.

Specifications of gyro-unit:

Type: Sperry Horizon Gyro Unit, type B. Accuracy of vertical direction:

Erection velocity:

$$
\begin{gathered}
1.5 \text { degree } \\
\text { ca. } \quad \begin{array}{c}
\text { degree } / \\
\text { min. }
\end{array} \\
\text { ca. } \quad 0.1 \mathrm{~V} / \text { degree }
\end{gathered}
$$

Sensitivity:

The subcarrier oscillators. The voltages of the roll and pitch potentiometers modulate the frequencies of two multivibrator-type subcarrier oscillators with central frequencies of 1300 and $2300 \mathrm{c} / \mathrm{s}, \mathrm{re}-$ spectively, in such a way, that the frequency deviations of the subcarriers are proportional to roll and pitch angle.

The subcarrier oscillators are followed by filter amplifiers to suppress all harmonics. In both oscillators and filter amplifiers use is made of transistors. The circuits are mounted on etched circuit cards.

Specifications of subcarrier oscillators:

Central frequency $f_{0}$

Max. frequency deviation $\Delta f_{\max }$

Stability freq. drift $/ \Delta f_{\max }$

Input voltage for max. deviation

Linearity (freq./input voltage, deviation from straight line)

Temperature drift $\left(\Delta f / \Delta f_{\max }\right)$

Amplifier output current

$$
\begin{aligned}
& 1300 / 2300 \mathrm{c} / \mathrm{s} \\
& \pm \quad 0.1 \mathrm{f}_{\mathrm{o}} \\
& 1 \% \\
& 1.2 \mathrm{~V} \\
& <5 \% \\
& <1 \% \text { per }{ }^{\circ} \mathrm{C} \\
& \max .4 \mathrm{~mA}
\end{aligned}
$$

Instrument assembly. A general picture of the instruments as mounted in the raft is given in Figure 7. All instruments and accumulators are packed in water-tight boxes. The transmitter is mounted in the mast foot on which the flanged mast is bolted. In the mast provisions are made for access to the transmitter for adjustment purposes. All electric connections from instruments and accumulators are made through a central switching box with removable watertight lid. Through this switching box accumulators can be loaded. Apart from this, the 
WAVE HEIGHT MEASURING EQUIPMENT

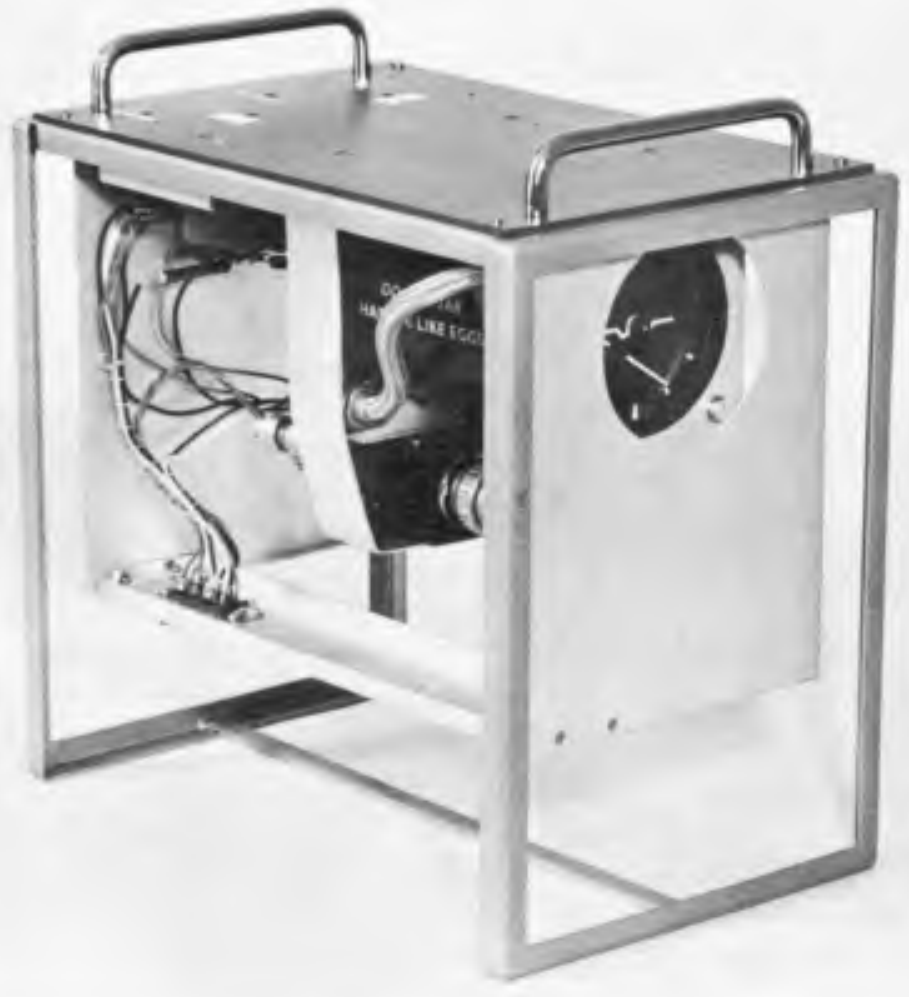

Fig. 6. Gyro unit.

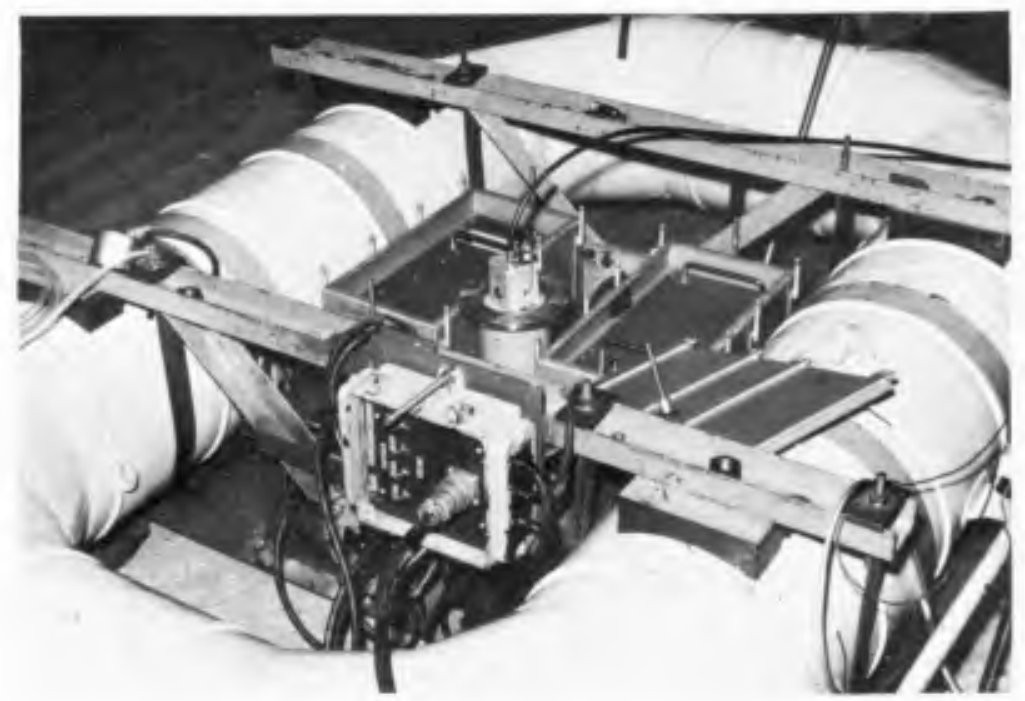

Fig. 7. Instrument assembly of wave meter . 


\section{COASTAL ENGINEERING}

gyro battery can be loaded with the gyro unit working. The reason for this is, that transportation hazards are minimum, when the gyro rotor is spinning, so that on transportation the gyro unit is always switched on.

\section{RECEIVING AND RECORDING INSTRUMENTS}

General scheme of receiving and recording system. A block diagram of the complete recefving and recording system is given in Figure 8 . The receiver is a special sensitive broadband $f . m$. receiver of good linearity. It can be switched to the receiving antenna, or to the calfbration oscillator. This calibration oscillator generates signals of the same kind as the wave meter transmitter, 1.e. a carrier with a central frequency of $157.75 \mathrm{Mc} / \mathrm{s}, \mathrm{f} . \mathrm{m}$. modulated by two subcarriers, with frequencies of $1300 \mathrm{c} / \mathrm{s}$ and $2300 \mathrm{c} / \mathrm{s}$, respectively.

A calibration switch, which is incorporated in the calibration oscillator circuit shifts the frequencies of carrier and subcarriers over an amount, corresponding to frequency deviations of the wave meter transmitter for known values of acceleration and roll and pitch angles. At the start and at the end of a recording period the receiver is switched to the calibration oscillator, and the calibration values are recorded. In this way the complete receiving and recording system can be kept under control, and errors can be eliminated or corrected.

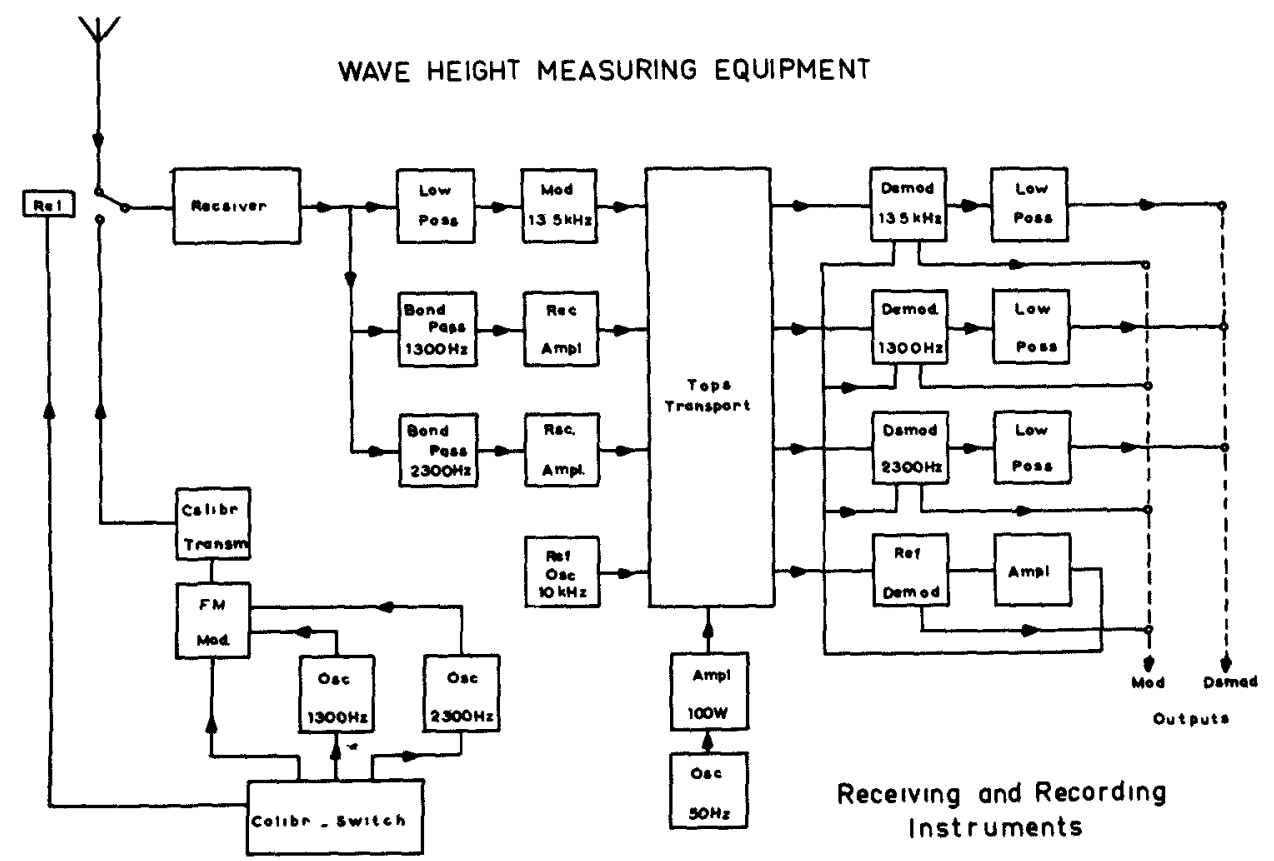

Fig. 8. Block diagram of receiving and recording system. 


\section{WAVE HEIGHT MEASURING EQUIPMENT}

The receiver output consists of the accelerometer signal together with the two subcarriers, containing the informa tion on roll and pitch angle. The three signals are separated by filters, and the accelerometer signal is $\mathrm{f} . \mathrm{m}$. modulated on a $13.5 \mathrm{kc} / \mathrm{s}$ subcarrier. Each of the three subcarriers is now recorded on a separate track of a 4 track magnetic tape recorder. On the fourth track a $10 \mathrm{kc} / \mathrm{s}$ reference signal of very accurate frequency is recorded. This reference signal is used for timing purposes on play back of the signal, and aloo for wow and flutter compensation.

The capstan motor of the tape recorder is driven from an amplifier, connected to a $50 \mathrm{c} / \mathrm{s} \mathrm{R}$.C. oscillator. The reason for this is, that in many cases main power of accurate $50 \mathrm{c} / \mathrm{s}$ frequency is not available.

The receiver. To obtain adequate sensntivity a superheterodyne receiver with double mixing is used. The first local oscillator is a crystal oscillator, whose frequency is multiplied by nine in a separate multiplier. The second local oscillator is an L.C. oscillator which has a ferrite modulator included. The i.f. stages, limiter discriminator are conventional. However, the discriminator output is fed back to the ferrite modulator of the second local oscillator. In this way three objectives are obtained:
a. good band width
b. good linearity
c. automatic frequency correction

The receiver has a balanced cathode follower output stage. A d.c. meter is connected over the output, indicating the frequency deviation. A second d.c. meter, connected to an a.m. detector, indicates signal strength.

Specifications :

Central frequency

Tuning range coarse

Band width fine

Stability (1 hour after switching on)

Sensitivity on antenna input

Linearity ( $\max$. deviation of straight line at

max. freq. deviation)

L.f. band width

$$
\begin{gathered}
157.75 \mathrm{Mc} / \mathrm{s} \\
\pm 1 \mathrm{Mc} / \mathrm{s} \\
\pm \\
\pm 00 \mathrm{kc} / \mathrm{s} \\
-150-\frac{\mathrm{m}}{ \pm} 300 \mathrm{~s} \\
3.10^{-5} \\
5 \mu \mathrm{V} \\
4 \% \\
0-7000 \mathrm{c} / \mathrm{s}
\end{gathered}
$$


The calibration oscillator. The calibration oscillator is a replica of the wave meter transmitter, except for the power stage. The oscillator is frequency modulated by d.c. and by two subcarrier signals of $1300 \mathrm{c} / \mathrm{s}$ and $2300 \mathrm{c} / \mathrm{s}$ central frequency, respectively. The subcarrier signals are obtained from subcarrier oscillators, identical to those of the wave meter. These subcarrier-oscillators are also frequency modulated by d.c. signals. By means of a calibration switch a number of voltages can be switched to the ferrite modulator of the calibration-oscillator and bot $h$ subcarrier oscillators. These voltages can be chosen as to represent exactly known values of acceleration and roll angle and pitch angle.

Specifications of the calibration oscillator are:

Carrier frequency

Roll angle carrier frequency

$157.75 \mathrm{Mc} / \mathrm{s}$

Pitch angle carrier frequency

$1300 \mathrm{c} / \mathrm{s}$

Calibration switch positions :

$\mathrm{c} / \mathrm{s}$

Acceleration $01 \pm 0.1 \mathrm{~g}+0.2 \mathrm{~g} \pm 0.3 \mathrm{~g} \mathrm{~m} / \mathrm{sec}^{2}$

Angles $\quad 0_{1} \pm 5^{\circ} \pm 10^{\circ} \pm 15^{\circ}$

The magnetic tape recorder. The advantage of ma gnetic recording is, that the recorded data can be easily reproduced and processed afterward For this reason this method of registration was chosen. The tape recorder is a four track instrumentation type recorder with $\mathrm{f} . \mathrm{m}$. subcarrier system. One track is used for recording an accurate $10 \mathrm{kc}$ frequency reference signal, which is used for wow and flutter compensation when analog signals are wanted on play back, and for timing purposes, when digital data processing is used. Since the data are available as f.m. modulated subcarriers, digital processing can be easily effected with electronic counters and gates.* The electronic part of the magnetic tape recorder is constructed as a rack with plug-in units.

Some specifications of the tape recorder are:
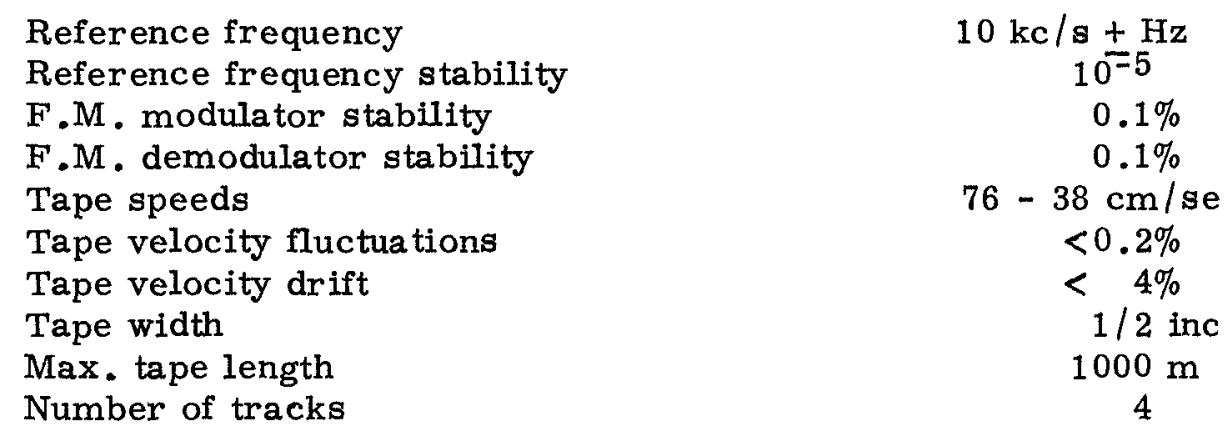

*F.M. modulated subcarrier output is obtained from the reading head amplifiers, analog output is bbtained from f.m. demodulator circuits. 


\section{WAVE HEIGHT MEASURING EQUIPMENT}

\section{SUMMARY}

The system as described is the result of a number of improvisations, when measurements were a pressing necessity. It is now possible to indicate certain points, where improvements are needed.

1. The raft may be constructed much lighter, so that it could be more easily handled; besides a more logical assembly of the instrumentation is possible.

2. The acceleration signal may be f.m. modulated on a l.f . carrier. Although the stability of a l.f. carrier is not necessarily better than the stability of a h.f. carrier, much wider frequency deviations are possible, with as a result a better signal to drift ratio.

3. Since the hydrodynamic properties of the raft are not well known, the accelerations in two horizontal directions should preferably also be measured. The angle between accelerometer axis and true vertical direction could then be more accurately calculated.

4. Tape speed and subcarrier central frequencies are not optimally chosen. Improvements of these could result in lower tape use and longer measuring periods.

5. The resonant frequency of the accelerometer is higher than necessary for the low frequency content of wave motion. This results in loss of sensitivity, since with lower spring constants higher deflections of the accelerometer mass could be obtained. 